\title{
Mapas, fronteiras e outras criaturas indomáveis em busca de identidade.
}

\author{
NIKOLETA KERINSKA
}

Nikoleta Kerinska é doutora em Artes Plásticas, Estética e Ciência da Arte pela Universidade de Paris I, Panthéon-Sorbonne (2014). Pesquisadora do grupo Fictions \& Interactions da Universidade de Paris 1 Panthéon-Sorbonne sob a coordenação de Bernard Guelton. Professora de arte computacional na Universidade Federal de Uberlândia. Sua pesquisa artística inspira-se pelas convergências/divergências nos processos de comunicação homemmáquina, que fazem uso da linguagem natural, como também pelas relações poéticas entre linguagem natural e imagem.

Lattes: http://lattes.cnpq.br/8402599923667945

Orcid:https://orcid.org/0000-0001-5486-1381 
- RESUMO

O presente texto elucida algumas questões substanciais da peça sonora de minha autoria "O discreto charme da democracia" (2018-2019). Ele se projeta além do limite do artigo acadêmico, recorrendo à plasticidade do ensaio literário, desejando que a escrita se emancipe da peça artística que é o seu primeiro elã. Sem visar uma dimensão metodológica do processo de criação, essa reflexão levanta algumas referências e laços sentimentais, esboçando uma breve análise dos elementos que motivaram o ato artístico: os mapas e as fronteiras que sintetizam o espaço e guiam as trajetórias. Enquanto o mapa apresenta a topologia do contexto de criação, as fronteiras, efetivadas como gestos gráficos, são vivas para contar suas histórias.

\section{- PALAVRAS-CHAVE}

Arte contemporânea, fronteiras, geopolítica, obra sonora.

\section{- ABSTRACT}

This text elucidates some substantial questions from my own sound art piece, "The Discreet Charm of Democracy" (2018-2019). The text has for ambition to go beyond the limits of the academic article, almost resorting to the plasticity of the literary essay, wishing for the writing to emancipate itself from the artistic work that is its first object. Without focusing on a methodological dimension of the creation process, this reflection raises some references and sentimental bonds, outlining a brief analysis of the elements that motivated the artistic act: maps, that synthesize space, and boundaries that guide the trajectories. While the map presents the topology of the context of creation, the boundaries' effect is to make the graphic gestures come to life to tell their stories.

\section{KEYWORDS}

Contemporary art, borders, geopolitics, sound work. 


\section{Tentativa de começo}

Numa segunda-feira de setembro, fria e luminosa, o programa "Caminhos da Filosofia", da rádio France Culture, dirigido por Adèle Van Reeth, começa com a voz terna de uma mulher, que, aos poucos, se agita: "Ah, você sabe, realmente não gosto da ideia de contar sua juventude, criticar os pais, sujá-los... Sou bastante ignorante, eu sei, mas tenho certeza de uma coisa: uma obra de arte não pode ser um acerto de contas, caso contrário, não é uma obra de arte..."1

Podemos concordar com essa afirmação - ou mesmo com qualquer outra que tenta definir previamente o que deve ser uma obra de arte? Não é por meio da obra de arte que o artista procura demarca a sua existência? Esta demarcação não seria, de uma forma ou de outra, um acerto de contas? Não se trata especificamente de um acerto de contas com a família - o mais tentador -, nem com a sociedade, ou com as convenções sociais do momento, mas consigo mesmo. Uma obra de arte se forma, inicialmente, dando voz aos fantasmas que habitam o artista, aos desassossegos e às titilações, que são seus impulsos vitais. E o que é, "afinal das contas", um "acerto de contas", senão uma tentativa de responder ao que julgamos antiético, injusto, desumano, ou, ainda, fazer valer nossa opinião, reivindicar uma posição? Parece que tudo isso tem muito a ver com a criação artística.

Ofereço essa curta divagação como preâmbulo ao relato a seguir, que é inspirado pela peça sonora "O discreto charme da democracia", cuja realização ocorreu entre novembro de 2018 e abril de 2019². O presente texto não busca analisar a peça, ou, dar uma dimensão metodológica do processo de criação. Seu objetivo é revelar as inquietações intelectuais, que acompanharam a criação da peça, assim como evocar alguns laços sentimentais e referências artísticas, que precederam e motivaram o trabalho, e, também, e ao mesmo tempo, propor uma reflexão que prescinde a fruição do trabalho artístico.

A peça sonora $\mathbf{O}$ discreto charme da democracia traz um interesse específico - o uso e a criação de mapas no campo da arte. O mapa é esse objetoguia que, para muitos artistas, revela circunstancialmente ideias e referências, caminhos e relações. Métodos próprios à cartografia e ao ato de mapear podem descrever o contexto de criação e sugerir a trajetória de uma obra. Em seguida, são postos alguns pontos que se interconectam feito fronteiras por linhas desregulares e que, por sua vez, podem sofrer interrupções, ou cair em abismos imprevistos, traçando tanto quanto possível uma teia de questões-chave. Por fim, a sequência sonora que surge dessas reflexões tenta contar como os mapas se esticam para efetivar o desenho de suas fronteiras - desenho vivo e mutável, que toma vida para se tornar narrativa.

\footnotetext{
1 Montagem sonora de Thomas Beau, com diferentes filmes de F. Truffaut do ciclo "Doinel ilustrando a evolução do personagem". Disponível em https://www.franceculture.fr/emissions/les-chemins-de-laphilosophie/philosopher-avec-francois-truffaut-14-cycle-antoine-doinel-la-naissance-dun-cineaste. Acesso em: 06/12/2019. No original: "Oh, tu sais, je n'aime pas trop cette idée de raconter sa jeunesse, de critiquer ses parents, de les salir... je suis assez ignorante, je sais, mais je suis certaine d'une chose c'est qu'une œuvre d'art ne peut pas être un règlement de comptes, ou, alors ce n'est pas une œuvre d'art..." .

2 Esta peça foi exposta pela primeira vez na exposição coletiva Geografias sensíveis: paisagens, territórios e fronteiras, de 03/05 a 30/06/2019, no Centro Cultural da UFMG, em Belo Horizonte. Audio disponível em: www.youtube.com/watch?v=cFUHWkEQNOA. Acesso em: 04/12/2019
} 


\section{Mapas}

A questão do espaço é um tema colossal nas artes visuais. Entre sua ocupação e sua representação, as formas, os formatos, os meios plásticos ou as intenções artísticas compõem um conjunto vasto e diversificado para o pesquisador artista. Entre todos os tipos de representação do espaço, sua transfiguração formal em superfícies achatadas e reformuladas em escalas humanas - ou seja, os mapas propriamente ditos - me parece uma das mais curiosas.

Para um geógrafo, um mapa é um instrumento fundamental para estudar e analisar o espaço. O mapa é a representação plana, reduzida e deformada da Terra ou de uma parte dela - digamos, uma representação visual sintetizada, que transcreve e relaciona propriedades e elementos geográficos de um local e suas relações com as localidades limítrofes. Roger Brunet define o mapa geográfico como "um modelo em escala" que "utiliza sinais convencionais descriptografados na legenda" e que traduz a esfericidade da Terra em um espaço plano por meio de uma projeção específica (Brunet, 1993). O geógrafo sinaliza também que:

"O espaço representado é, portanto, sempre deformado: qualquer mapa é uma anamorfose. Os mapas podem [...] representar fenômenos [...] invisíveis, associações de fenômenos e até estruturas dinâmicas; eles se tornaram um instrumento extremamente poderoso de descoberta geográfica, o que por si só levanta amplos problemas na explicação das distribuições, disparidades e estruturas espaciais que eles revelam [...]" (Brunet, 1993, p.89).

Nesse sentido, o mapa é uma conquista racional do espaço - sua abstração em direção a uma totalidade visual. Contudo, ousarei um outro olhar para pensar o mapa: uma cidade do tamanho de Paris pode ser atravessada em aproximadamente duas horas e meia ao se caminhar do parque La Villette em direção sul até a Cidade Universitária. Para vencer esse espaço, é necessário investir forças físicas e mecanismos psíquicos e perceptivos, ativar a orientação espacial e a memória. Ao longo desse trajeto, provavelmente, diversos eventos interpelariam a atenção do caminhante, subjetivando essa experiência e constituindo significados, transformando o espaço percorrido em um laboratório sensorial. Se, porém, o caminhante tentar visualizar o trajeto no mapa de Paris - (ou, ainda, da França), ele localizará um minúsculo traço ou um ponto preto - uma síntese da representação espacial em escala geográfica.

O mapa é, portanto, a concretização da discrepância absoluta entre experiência e representação, entre corpo e espaço, entre subjetivação e abstração. Um mapa contém tudo, sem nada mostrar - e é talvez essa sensação um tanto axiomática que o faz um objeto incontornável para o imaginário artístico. O mapa enquanto imagem será sempre uma 'imagem - devedora', mas também uma 'imagem - provocação', que incita a ser destrinchada, extirpada ou metamorfoseada. O mapa diz ao artista: "vá além da superfície!"

Afirmo aqui que um artista inquieto por compreender os desafios de seu tempo e o espaço no qual evolui dificilmente ficará indiferente perante os mapas. Três grandes projetos curatoriais são testemunhas da sedução que, os mapas exercem sobre os artistas e os curadores de arte: a exposição Mapping organizada 
por Robert Storr em 1994 no MOMA (Museum of Modern Art) em New York, a exposição GNS, com a curadoria de Nicolas Bourriaud em 2003 no Palais de Tokyo, e o projeto A vastidão dos Mapas, com a curadoria de Aginaldo Farias, realizado nos anos 2017 e 2018 em diversas instituições culturais no Brasil. Cada uma dessas exposições, é, em si um fenômeno cultural distinto que traz um conjunto de ideias original. Não obstante, fixa-se um ponto de convergência entre as três: o interesse artístico pela representação do espaço, pela prática da cartografia e pelo objeto mapa.

A exposição Mapping apresenta artistas reconhecidos internacionalmente, como Sol LeWitt, Richard Long, Robert Smithson, Adriana Varejão, Waltércio Caldas, Annette Lemieux, e Guy Debord. O título da exposição indica sem ambiguidade a intenção do curador - mapear, ou mais precisamente, expor o ato de mapear, de localizar e precisar posições. Robert Storr parte de seguinte constatação: "Enquanto as pinturas podem alcançar uma estranha semelhança com as coisas do mundo que representam, os mapas do mundo são, por si e naturalmente, suas próprias abstrações. Quanto maior seu escopo e mais específicos seus propósitos, mais óbvio isto se torna"' (1994, p.5).

Para o curador, o mapa é esse instrumento que permite ver além. Ele afirma: "O mundo é um todo do qual só podemos perceber as partes. Uma visão de fato abrangente é matemática ou divina " (Storr,1994, p.6). O desejo de ver e a visão do artista se somam, assim, para suplantar essa incompletude, para a qual o corpo humano, considerado em sua escala natural, é a primeira barreira.

Realizada quase dez anos depois, a exposição GNS coloca a questão da topografia no centro da criação artística, procurando destrinchar os fatores que motivam a representação do mundo contemporâneo. Os Sistemas Globais de Navegação por Satélite, unidos sob a denominação GNS, usam satélites e receptores para determinar a localização de algo, rastreando seu posicionamento em qualquer ponto da superfície terrestre.

Por meio de investigação, exploração, levantamento e análise de dados, os artistas reunidos na exposição GNS apresentam obras que produzem formulários, visualizam o tratamento de informações, ou projetam diagramas e criam documentos. Essa exposição mostra não só que a geografia no início do século XXI dispõe de métodos radicalmente diferentes dos conhecidos até então, mas também revela que seus conhecimentos e instrumentos são mais do que nunca um campo (sísmico) para o pensar artístico.

O terceiro projeto curatorial de grande porte cujo tema são os mapas e sua repercussão na arte contemporânea é $\mathbf{A}$ vastidão dos Mapas $^{5}$. Realizado por Agnaldo Farias, este projeto coloca em relação a coleção de mapas originais do continente latino-americano do século XVI ao sec. XVIII do Banco Santander-Brasil com uma seleção de obras de artistas contemporâneos, evocando desse modo

\footnotetext{
3 No original: "While paintings may achieve an uncanny resemblance to the things in the world they depict, maps of the world are by their very nature abstractions. The greater their scope and the more particular their purposes, the more obviously the fact asserts itself."

4 No original: "The world is a whole of which we can only perceive the parts. An all encompassing view is mathematical or divine."

5 Cathttps://cms.santander.com.br/sites/WPS/documentos/Arq-generico-exposicaomapas-4/18-0529_184054_a+vastidao+miolo+muna+qrcode_site+integral.pdfalogo integral da exposição disponível em . Acesso em: 04/12/2019.
} 
uma visão ontológica do mapa. Para o curador, "o coração da mostra" são justamente esses mapas antigos, que desenham, de forma desregular, a costa brasileira e indicam a entrada no continente com a anotação: "terras não descobertas" (Faria, 2018, p.20). São elas - as terras desconhecidas, que ainda serão saboreadas e cartografadas - que se abrem como "terras de sonhos, de toda sorte de projeções e fantasias por parte dos que se propunham descobri-las", diz o curador. Guiado pelo seu olhar, o público explora os tempos distantes dessas geografias. Tempos que conferem a essas geografias a dimensão própria da imaginação, encontrando assim a afirmação de Christian Jacob e Mark Monmonier, segundo a qual o mapa é uma projeção da mente, antes de ser uma imagem da terra (1993).

Não se deve esquecer que cartógrafos e artistas compartilham do mesmo universo material do desenho, e, talvez do mesmo desafio da observação e da imaginação. Os primeiros cartógrafos são uma espécie de anatomistas do espaço, cuja ciência passa pelo mito, pelo relato e pelo testemunho, mas também pela feitura de imagens. Desvendar o espaço para sintetizá-lo num plano, extrair o essencial da paisagem, esquematizar em escala as distâncias invencíveis para o corpo humano: todas essas ações ambicionam, antes de mais nada, o conhecimento.

Ao longo dos séculos, a cartografia como técnica de organizar e visualizar o conhecimento se estende para inúmeros campos, afirmando sua eficiência. Atualmente, existem mapas topográficos, temáticos ou especializados, mapas de reconstituições históricas ou de visualização de processos dinâmicos (Rystedt, 2014). Os mapas oferecem inesgotáveis possibilidade de pensar a realidade, de externalizar relações diversas entre seus elementos (mesmo os mais díspares), de criar narrativas e de visualizar contextos dinâmicos.

Dito isso, proponho pensar o mapa dentro de uma metodologia de criação, ou seja, como um instrumento para o artista. Assim, o mapa seria um instrumento fundamental no processo de criação, que permite esboçar ideias - que, em certos casos, precedem a obra. O mapa também pode ser usado para visualizar relações entre objetivos e intenções, pesquisas e soluções técnicas investigadas ao longo do processo de criação. Nesse sentido, o mapa se apresenta como um recorte que delimita o espaço-tempo da concepção de uma obra. Ele pode ser um documento, um diário de bordo, um panorama de conceitos, ou todo tipo de vestígio físico, que possibilita a reconstituição das ações do artista.

A peça sonora $\mathbf{O}$ discreto charme da democracia, motivo deste artigo, é fruto de um mapa, cuja primeira delimitação é a necessidade de fazer uma retrospectiva do tempo passado fora do meu país de origem - a Bulgária. A história recente da Bulgária, como um dos países do bloco do Leste Europeu, é por si um tema singular para análises geopolíticas. As transformações brutais que atingiram a sociedade com a chamada "redemocratização" do país, com a implementação da lógica de mercado capitalista e a adaptação das leis e das estruturas públicas a esse sistema, completam neste ano três décadas. E, talvez, o único parâmetro que pode ser medido com exatidão e objetividade neste caso é o tempo.

As mudanças socioeconômicas ao logo dessas três décadas configuram hoje um país destruído, esgotado e incapaz de se libertar dos esquemas de 
corrupção enraizados no governo dos últimos anos. Empobrecimento da população, economia fraca, agricultura quase inexistente, instituições de ensino precarizadas e um sistema de saúde em colapso - esse é o cenário de um país marcado por uma crise demográfica, que já é considerada uma verdadeira catástrofe: segundo estatística publicada por DataMacro no ano 1988 a população da Bulgária era de 8976255 pessoas - número que no ano 2018 foi reduzido para 7 $000039^{6}$.

Mas esse cenário caótico e desastroso, que nada mais é do que as ruínas de uma civilização, soma-se a lembranças da minha infância. Nessas lembranças, as fábricas funcionam, os campos são trabalhados e a colheita é generosa, cada escola conta com um pediatra e um dentista, e cada bairro, com uma 'policlínica', que atende a população gratuitamente. Nessas lembranças, ninguém é muito rico, e ninguém é muito pobre: no mesmo andar moram um trabalhador, um motorista, um cientista e um engenheiro. Todos os mercados têm os mesmos preços, e a variedade de produtos é quase inexistente. Não há moradores de rua, nem crianças mendigando nos semáforos. Nas escolas, romances como David Copperfield e Os miseráveis são lidos para lembrar o passado, e para reforçar a ideia de que a miséria e a pobreza foram vencidas junto com a Alemanha na Segunda Guerra Mundial.

Este é, grosso modo, o mapa da peça O discreto charme da democracia, que se desenha entre fatos, estatísticas e memórias. A peça surge do impasse entre a impossibilidade de formular verbalmente a minha indignação e a incapacidade de esquecer o passado recente. Entre elementos desse mapa, entre suas indicações geográficas, - um traço retém a minha atenção: a fronteira. A fronteira é a veia dos mapas, é o que dá organicidade a suas extensões: uma marca gráfica provedora de significados, mas também uma contradição em si, enfim, um fenômeno paradoxal

\section{Fronteiras}

Fronteira é, sem dúvida, uma das palavras que marcaram o curso do século XX. Demarcar, estabelecer ou proteger, atravessar ou invadir, redesenhar ou apagar, remover, abrir - todos esses verbos definem o destino das fronteiras, ao mesmo tempo que contam suas histórias. A fronteira é essa abstração enigmática, transcrita graficamente sobre o mapa, que nos protege ao mesmo tempo que nos isola, nos une aos que são nossos semelhantes (seja por língua, seja por nacionalidade) e nos separa dos nossos vizinhos, ou, de uma maneira geral, dos outros, os diferentes de nós.

Stéphane Bodénès escreve:

"Toda fronteira, inscreve no tempo um espaço geográfico, e o fossiliza. O limite de um estado resulta de circunstâncias históricas, específicas

e datadas, de uma relação de forças, de um emaranhamento de causalidades relacionadas a um contexto particular - tudo isso atua

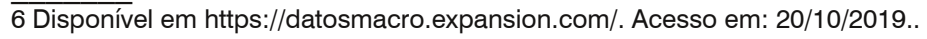


em uma complexa sinergia" (Bodénès, 1996, p.33).

Aprendemos, assim, o significado do termo fronteira, simultaneamente aos sentidos dos verbetes "país", "nação", "língua", "pátria". A fronteira é, portanto, um dos pilares definitórios das civilizações contemporâneas. Diríamos então: a fronteira é algo real e palpável?

"Não há nada mais artificial na natureza do que uma fronteira política; paradoxalmente, essa fronteira parece aos habitantes de seus países, e, frequentemente, a seus políticos como perfeitamente natural", afirma Emmanuel Ganon, pesquisador e diretor do projeto Observatoire Européen de Géopolique (2003, p.65). Segundo o autor, a fronteira que circunscreve um território, é fundamentalmente uma construção legal e jurídica. Além da territorialidade que a fronteira delimita, ela estabelece também as respectivas competências de dois sistemas estatais, de ambos os lados do seu traçado (ibid.). Nesse sentido, a fronteira é um elemento operacional dentro dos sistemas políticos, implicado diretamente em seu funcionamento, de onde provém a sensação de estabilidade (fortemente ilusória) que ela causa.

Se analisarmos a fronteira, sua definição e manutenção num plano histórico, compreenderemos como seu significado é um valor fundamental para uma comunidade. Para Stéphane Bodénès, "toda história da humanidade se resume, para cada comunidade, em uma busca muitas vezes patética pelo que, subjetivamente, é percebido como sua 'boa' fronteira" (1996, p. 34). A memória coletiva que se tece sobre o território habitado é impensável sem a noção de fronteira, sem o seu desenho. Ou seja, cada população adere "mais ou menos a um ou outro mito fundador de inspiração histórica, geográfica, sociológica, ética, religiosa ou outra" (ibid.), para alegar a importância da localização de suas fronteiras.

Deste modo, a fronteira pode ser vista como um mecanismo geopolítico, glorificado como um traço sagrado, cujo objetivo é delimitar um espaço interior, para servir ao aparato e à ideologia de um dado Estado. Nesse sentido, a ideia de abolir as fronteiras em busca de mais liberdade, união e igualdade entre os povos emerge naturalmente. Não se deve esquecer que para muitos intelectuais, a passagem do século XX para XXI, marcada pelos rápidos avanços tecnológicos, romperia, de maneira definitiva, as fronteiras interestaduais.

Os ventos das promessas mundialistas começaram soprar com o fim da "cortina de ferro" e a queda do Muro de Berlim. A "cortina de ferro" é um termo que enferrujou no século passado. Churchill o usou em 1945, importando-o do filósofo russo Vassili Rozanov (1918), como bem nos lembra Claude Quétel (2012, p.135137), para fazer referência à fronteira não declarada entre os países do Leste Europeu aliados à União Soviética e aos países capitalistas da Europa Ocidental.

Pouco antes do fim da segunda Guerra Mundial, na conferência de Yalta ${ }^{7}$, Stalin, Churchill e Roosevelt entram em acordo para apresentar uma frente unida no

\footnotetext{
${ }^{7}$ A conferência de Yalta acontece de 4 a 11 de fevereiro de 1945. O objetivo principal desse encontro entre os dirigentes das três potências mundias os Estados Unidos, a Inglaterra e a União Soviética é a elaboração de uma estratégia comum para acelerar o fim da Segunda Guerra Mundial, mas também definir o destino da Europa após a derrota do Terceiro Reich, e, garantir a estabilidade da nova ordem mundial após a vitória das forças aliadas. A divisão da Europa em 'zonas de influência' no período pós-guerra, somados à invenção e os testes da bomba atômica, levam à "Guerra Fria", cuja dinâmica marca as geopolíticas mundiais até 1989.
} 
planejamento da campanha final contra as tropas alemãs e japonesas, além da limitação do avanço do Exército Vermelho na Europa Central. Neste exato momento é feito o desenho da 'cortina de ferro' que se tornou o tracejado político mais significativo e determinante nos anos seguintes. Claude Quétel descreve a "cortina de ferro" de seguinte maneira:

'A 'cortina de ferro' entre o bloco Leste e o bloco Oeste conta com 8500 quilômetros de fronteiras fortificadas. Não estamos longe da Grande Muralha da China; desta vez trata-se não de preservar o império de invasões, mas de garantir a permanência das populações nele" (Quétel, 2012, p.142).

A primeira função da "cortina de ferro" durante todo o período de sua existência, é, obviamente, dificultar o trânsito livre de pessoas, mas também o trânsito livre de informações. Sua missão maior é manter um vacum inviolável entre os sistemas capitalista e socialista, para garantir seus respectivos funcionamentos. Hoje, olhando para o tempo passado e resgatando as lembranças dessa época, diria que medos semelhantes alimentavam os dois lados da "cortina de ferro": do lado leste, os líderes dos partidos temiam o retorno do capital, e a insubordinação popular demandando democracia e liberdade de expressão; enquanto isso, do lado oeste, o crescimento dos partidos de esquerda e o fortalecimento dos sindicatos (que poderiam eventualmente organizar a revolta dos trabalhadores) assombravam as forças econômicas capitalistas. Não obstante, uma vez os medos vencidos, no fim de 1989, a "cortina de ferro" fundida e o Murro de Berlim demolido, o triunfo da liberdade projeta-se com esperanças inestimáveis, rumo à mundialização.

A ideia do mundo sem fronteiras é propulsionada, também, pela fundação da União Europeia (UE) com o Tratado de Maastricht em 1992, logo após o fim da guerra fria. Os principais objetivos do Tratado são promover o progresso econômico e social equilibrado e sustentável, e, por meio da criação de uma área sem fronteiras internas, alcançar um nível superior de emprego e um fortalecimento socioeconômico no continente Europeu. Sua maior conquista é a criação de uma moeda única - o euro, cujo valor alto e estável enfrentará o dólar americano no mercado internacional. Os cidadãos europeus seriam os primeiros a experimentarem um trânsito sem fronteiras e a integração continental de populações cultural e linguisticamente diversas. Para os mais otimistas, o projeto da Comunidade Europeia poderia ser pensado a longo prazo numa escala planetária.

Mas no ano de 2019, após uma série de crises econômicas e migratórias, causadas em partes pelos conflitos no Oriente Médio, que tiveram como resultado a tentativa (até o presente momento malsucedida) da implementação do Brexit, ou, ainda, considerando as dificuldades de efetuar políticas tributárias e econômicas comuns entre os países membro da EU, fica claro, que manter a união dos países europeus é um desafio a ser enfrentado. Concordo, portanto, sem excitação, com a frase do cientista politico Ivan Krastev segundo a qual "a União Europeia sempre foi uma ideia em busca de realidade" (2017, p.13).

A globalização, estruturada pelas indústrias, pelas tecnologias de ponta e pelas telecomunicações, descreve um mundo cada vez mais informado, mas também cada vez mais desigual. E, curiosamente, enquanto se espera, que o planeta se torne a aldeia global e interconectada profetizada por Marshall McLuhan, nascem novas formas de distanciamento, de isolamento e de divisão entre as 
populações. Vinte e sete mil quilômetros de novas fronteiras foram traçadas desde 1991, especialmente na Europa, e em suas regiões limítrofes com a Ásia; dez mil outros muros, barreiras e cercas sofisticadas estão programadas a serem erguidas nos próximos anos; e, entre os anos 2009 e 2010, o geógrafo Michel Foucher contou 27 conflitos de fronteiras graves entre Estados (Debray, 2010, p.19). Com esses dados, fica claro que os riscos traçados pelas fronteiras são mais importantes do que em qualquer época precedente.

Condenando a globalização e seus efeitos econômicos, ecológicos e sociais, Regis Debray nos incita a pensar a fronteira como algo essencialmente humano: "A fronteira é primeiramente uma questão intelectual e moral", diz o pensador (2010, p.16). Em seu livro Elogio as fronteiras (2010), Debray nos convida a aceitar as fronteiras como o mecanismo que garantirá a diversidade cultural dos povos. Sem disfarçar um certo sarcasmo, ele define a ética "sem fronteiras" do mundo globalizado, como uma tendência que atrai grandes "simpatias e subvenções", e cujos admiradores se gabam estampando em seus cartões de visita "abre-te Sésamo". Escarnecendo desse entusiasmo, o pensador enfatiza: o projeto "fiscais de alfândega 'sem fronteiras' é para amanhã" (2010, p.11 $-12)$.

Segundo esse ponto de vista, a tentativa de preservar as fronteiras encarnará a luta contra o capitalismo globalizado. A fronteira é a porta que regula o trânsito, que demonstra a hospitalidade, que recebe, mas que também expele. Onde não há fronteiras, há guerras ou muros, afirma Debray. A fronteira tem também um valor simbólico:

"Os animais delimitam um território como próprio por um traço interveniente, olfativo ou auditivo. Limite móvel e difuso, que vai e vem com as estações do ano, e com o equilíbrio de forças entre espécies e populações. Nós, humanos, precisamos instituir: plantamos signos, erigimos emblemas", escreve Debray (ibid. p.10-11).

O elogio da fronteira é uma ode contra o imperialismo e "contra as potências econômicas que se sentem em casa em qualquer lugar no mundo", declara o autor (2010) ${ }^{8}$. Debray introduz a ideia de que a ideologia "sem fronteiras" é a ideologia dos ricos e fortes, enquanto a fronteira é um "limite hospitaleiro que garante a diversidade do mundo" (ibid). Os fracos necessitam sempre de uma fronteira para se proteger e para garantir sua segurança, para não serem devastados pelo tsunami global.

A temporalidade das fronteiras é uma questão que me interessa particularmente. A experiência de ver as fronteiras do Leste Europeu, e especialmente dos Bálcãs, se transformarem de maneira radical, logo após a conclusão do meu segundo grau, ou seja, logo após ter memorizado essas fronteiras que pareciam de uma estabilidade inabalável, foi para mim (e para muitos outros como eu), um choque violento. Mais do que a porosidade ou a envergadura de uma fronteira, sua (não) durabilidade traz uma problemática própria.

Stéphane Bodénès pensa a temporalidade das fronteiras a partir da premissa humana:

\footnotetext{
$\overline{8}$ Palestra de Régis Debray, publicada no canal PhilO do youtube, "Eloge des frontières" de 3 de dezembre 2010, disponível em https://www.youtube.com/watch?v=fMZbyOfMNcg. Acesso em: 19/06/2019. .
} 
"Se a fronteira tivesse idade, a definição dessa última traria um problema: "antiga" ou "recente" não significa um limite de estado, do mesmo modo que, para o homem as escalas de tempo não podem se sobrepor. Uma vida humana permanece um parâmetro inaceitável para designar a antiguidade de uma fronteira, pois a derrisória face do tempo da história se estende por milhares de anos." (Bodénès, 1996, p.33)

Para desenvolver a ideia segundo a qual a longevidade de uma fronteira, em muitos casos, escapa à percepção humana - e, portanto se torna um valor abstrato - Bodénès dá alguns exemplos concretos:

"O caminhar histórico comprova a sucessão diacrônica de "verdades" furtivas, lacunares e subjetivas: as evidências de 3 séculos ou de 30 anos atrás não existem mais. Se alguém tivesse dito para um bourguignon do séc. 13 , para um escocês do séc. 15 , ou para um tirolês do séc. 19, que eles se tornariam respectivamente cidadãos francês, britânico e italiano, muito provavelmente isto causaria grande espanto!"(ibid.).

Compreendemos que o autor não analisa os momentos de ruptura, quando uma fronteira deixa de ser o que é. Efetivamente, o que lhe interessa é a mutabilidade das fronteiras - característica a partir da qual uma fronteira pode ser pensada como um ser vivo, que evolui em busca de uma identidade ou em seu abandono. Sua temporalidade, mesmo numa escala muito diferente da temporalidade humana, denuncia sua fragilidade e seu caráter provisório, raramente considerados nos discursos políticos. Desse modo, a fronteira se "estica aqui ou ali durante alguns séculos, mas, à luz do termo histórico, é corroída pela senescência" (Bodénès, 1996, p.33). De natureza paradoxal - bem definida, porém mutável, concreta e ao mesmo tempo abstrata, tanto artificial quanto indispensável -, a fronteira, de maneira semelhante ao mapa, intriga pela sua capacidade de síntese.

A peça sonora $\mathbf{O}$ discreto charme da democracia surge do desejo de resgatar o mapa da minha infância com as suas fronteiras, mesmo que uma parte delas se tenha fundido junto com a "cortina de ferro", naquele outono de 1989, que prometia a primavera da democracia. A democracia veio a ser um conceito profundamente estudado, com todas as suas peculiaridades e possíveis desdobramentos - um tema de repercussão inesgotável, como um artigo de luxo importado do oeste, ou como um exercício miraculoso, que uma vez apreendido e praticado, traria todas as soluções para as angústias sociais. A democracia continua sendo uma lição teórica, de complexidade considerável. Muitos cidadãos do Leste Europeu afirmariam hoje, três décadas mais tarde, que a democracia não passa de uma miragem, de um sonho de liberdade, e que sua conquista é uma utopia que perdeu por completo sua sedução.

Eis uma situação perturbadora, que inspira a criação da peça sonora 0 discreto charme da democracia - a fronteira que ficou gravada como uma tatuagem, ou como uma cicatriz, preservou suas linhas idênticas desde sempre, mas o seu desenho hoje corre em um mapa que não consigo mais reconhecer. Os relevos desse mapa, suas dobras e extensões, falam a minha língua materna, mas as frases que eles emitem não têm mais sentido algum. Com entonações 
incompreensíveis, componentes geográficos íntimos balbuciam e narram a paisagem de uma tragédia social, econômica e moral. Resumindo: um sistema capitalista em estado de implementação.

Assim, a fronteira, na minha peça sonora, é um grafismo por excelência. Seu contorno fino em forma de um leão ${ }^{9}$, cujo conteúdo apagou-se nas últimas três décadas, faz lembrar tudo que aí existia e deixou de ser. Toda uma geografia desapareceu. Segundo Bodénès, a fronteira se assemelha a "uma sucessão diacrônica de verdades" (1996, p.33). A afirmação encanta pela sua exatidão, mas como levar adiante a "sucessão de verdades" sem questionar as mutações do espaço que as abriga? Como entender que é a fronteira sendo sempre a mesma, passa a transcrever uma realidade radicalmente diferente? Perguntei-me insistentemente como desenhar essa fronteira - e a única forma que achei foi: pelas palavras.

\section{Sonoridades}

A princípio, a concepção de um trabalho de arte leva as marcas da intenção do artista, que em certas vezes, precede a ação. Na intenção artística, a obra existe em estado embrionário, como um pensamento que procura sua composição lógica e sua verbalização. A intenção do artista se alimenta também, de maneira cega e intuitiva, da necessidade de criar. É esta necessidade que, segundo René Untereiner, fundamenta a obra: "É na necessidade de criar que devemos buscar a verdadeira origem da arte, e não na arqueologia ou no passado, [...]" (1960, p.292). A intenção e a necessidade determinam o meio e as ações artísticas, guiando as experimentações e as escolhas do artista. No caso da peça sonora, inspiração primeira desta reflexão, a linguagem natural foi escolhida como meio de realização da obra.

A peça tem duração de 9 minutos. Nesse tempo, duas falas se entrelaçam uma voz que cita dados de estatísticas da produtividade econômica da Bulgária dos anos 1989 e 2014, e outra que narra lembranças e sensações. Ou seja: uma que compara números, e outra que cria imagens. A paisagem sonora que acolhe essas falas se transforma e se densifica, acompanhando suas evoluções.

Imagino que essa escolha se deu em função das virtudes expressivas da palavra, mas também pela sua capacidade narrativa e psicanalítica. Sabe-se que a palavra falada é usada para aliviar o sofrimento moral e físico de diversas formas. A medicina, a magia, a religião, ou o xamanismo recorrem à palavra como meio construtivo de suas práticas. $\mathrm{Na}$ arte, o uso da linguagem escrita ou falada transfigurou todo um campo de pesquisa com problemática própria ${ }^{10}$. Nesse caso específico, optei pelo uso da linguagem por motivos tanto conceituais quanto formais.

O formato da peça sonora permite fazer uma composição entre a minha língua materna, o búlgaro, e o português, minha língua ativa. O português é a língua

\footnotetext{
9 O mapa da Bulgária apresenta a silhueta de um leão (ver https://bulgaria-map.info/maps/BulgariaEncarta.png.)

${ }^{10}$ As relações entre texto e imagem são estudados sob várias perspectivas. Podem ser citados os estudos de W.J.T. Mitchel, Meyer Schapiro, Hubert Damisch, entre outros.
} 
na qual me projeto por longos períodos da minha vida - minhas anotações, aulas, meus diários são escritos em português. Usá-lo simultaneamente com o búlgaro, além do contraste sonoro, me trouxe a possibilidade de criar um jogo de significados que demonstram os limites da linguagem. Passar de um registro linguístico a outro torna palpáveis os limites operacionais de uma língua falada. Entendo também que a palavra não transmita somente uma informação, mas é usada para provocar, questionar, evocar outras palavras e reações. Em suma: a palavra é um problema ético.

"A vida é o conjunto de funções que resiste à morte", escreve Bichat. Parafraseando o grande médico, diria: a narrativa é o conjunto de palavras que resiste ao esquecimento. E este é o segundo motivo para falar de mapas e fronteiras do passado, que desenharam a minha infância, e que exigem agora um texto. A infância, que se distancia lentamente, mas de maneira decisiva, junto com uma época excepcional do ponto de vista politico e social, me interpela para contála. Sem saudosismo, se possível! Mais uma afirmação de que existiu.

\section{REFERÊNCIAS}

BODENES, Stéphane. "Frontière et temporalité", In: Zwahlen René, Bailly Antoine. Editorial. Le Globe.

Revue genevoise de géographie, tome 136, 1996; disponível em: https://www.persee.fr/doc/globe_0398-3412_1996_num_136_1_1357. Acesso : 23/12/2019.

https://doi.org/10.3406/globe.1996.1357

BRUNET, Roger. "Les Mots de la géographie", in BRUNET, Roger; FERRAS, Robert \& THERY, Hervé Thery. (org.) coll. Les Mots de la Géographie, dictionnaire critique. Paris: Reclus, La Documentation Française, 1993.

DEBRAY, Régis. Éloge de frontières. Paris : Ed. Gallimard, 2010.

FARIAS, Agnaldo. A vastidão dos Mapas, catálogo de exposição. São Paulo: Ipsis, 2018.

GONON Emmanuel. "Fronière et territoire: Une symbiose incertaine" In, Le territoire pensé: Geographie des représentations territoriales, org. Frédéric Lasserre \& Aline Lechaume, Quebec, Presses Universitiares de Quebec, 2003.

JACOB, Christian \& MONMONIER Mark. "Ce que disent les cartes" in Le Monde. Publicado 06 de agosto de 1993. Disponível em :https://www.lemonde.fr/archives/article/1993/08/06/ce-que-disent-lescartes_3941873_1819218.html. Acesso : 23/12/2019.

KRASTEV, Ivan. Le Destin de I’Europe. Paris: Premier Parallèle, 2017.

QUETEL, Claude. Murs: une autre histoire des hommes. Saint-Armand-Montrond: Ed. Perrin, 2012. https://doi.org/10.3917/perri.quete.2012.01

RYSTEDT, Bengt. "Cartographie", CFC, №221- Septembre, Suécia, 2014. Disponível em: 
http://www.lecfc.fr/new/articles/221-article-3.pdf. Acesso em: 15/11/2019.

STORR, Robert. Mapping. New York: PublisherThe Museum of Modern Art: Distributedby H.N. Abrams, 1994.

UNTEREINER, René. "Réflexions sur la création artistique". In: Bulletin de I'Association Guillaume Budé, $n^{\circ 2}$, juin 1960, (pp. 285-293).

Disponível em: www.persee.fr/doc/bude_0004-5527_1960_num_1_2_3902. Acesso em: 04/01/2020.

https://doi.org/10.3406/bude.1960.3902

Recebido em 10/01/2020 - Aprovado em 20/03/2020

Como citar:

Kerinska, N. T. (2020). Mapas, fronteiras e outras criaturas indomáveis em busca de identidade. OuvirOUver, 16(1), 70-83. https://doi.org/10.14393/OUV-v16n1a202052257

(c) (i) (8) $\begin{aligned} & \text { A revista ouvirOUver está licenciada com uma Licença Creative } \\ & \text { Commons Atribuição-NãoComercial } 4.0 \text { Internacional. }\end{aligned}$ 